\title{
La metáfora del pasado en la narrativa de Vincenzo Consolo'
}

\author{
The Metaphor of the Past in the Narrative of Vincenzo Consolo
}

\author{
CAROLINA MARTÍN LÓPEZ \\ Universidad de Málaga \\ España \\ cimartin@uma.es
}

(Recibido o6-O3-20I4; aceptado I3-II-2OI4)

Resumen. El artículo plantea una lectura de la narrativa de Vincenzo Consolo a través de la dialéctica que la metáfora del pasado histórico, literario y lingüístico entabla en el tejido intertextual de su escritura. Los periodos históricos que Consolo elige como fondo y escenario por el que transcurren las vicisitudes y experiencias de sus personajes han sido de crucial importancia en la historia nacional italiana y, precisamente por ello, son altamente recurrentes como representación del presente al que alude el autor. Para expresar la concepción del mundo en que vivimos y su posible actuación en él es asimismo imprescindible para Consolo la exigencia de la metáfora topográfica, de la metáfora del nostos (de la cita constante del viaje de regreso narrado en la Odisea) y la recuperación de términos lingüísticos del pasado capaces de contrarrestar la vacuidad terminológica de los medios de comunicación de masas.

Palabras clave: Vincenzo Consolo; literatura italiana contemporánea; metáfora histórica; metáfora topográfica; memoria literaria y lingüística.
Abstract. This essay suggests a reading of the literary production of Vincenzo Consolo through the dialectic that the historical and literary and linguistic metaphor establishes in the intertextual tissue of his writing. The historical periods which Consolo chooses as the background and scenery for the vicissitudes and experiences of its characters have been of crucial importance in Italian national history, and precisely for this reason, they are highly recurrent as a representation of the present this referred to the autor. To express the conception of the world in which we live, and its possible action on it, is an essential way for Consolo to resort to the topographic metaphor and the metaphor of nostos (of the omnipresent quote of the return journey narrated in the Odyssey), and the recovery of linguistic terms of the past. It is an entire lexical heritage capable of counteracting the emptiness of the terminology of mass communications media.

Keywords: Vincenzo Consolo; Contemporary Italian literature; historical metaphor; topographic metaphor; literary and linguistic memory.

\footnotetext{
I Para citar este artículo: Martín López, Carolina (20I5). La metáfora del pasado en la narrativa de Vincenzo Consolo. Álabe 11. [www.revistaalabe.com]

DOI: IO.I5645/Alabe.2OI5.II.7
} 
Vincenzo Consolo, fallecido sólo hace unos años (2OI2), definía gran parte de su producción narrativa como una macro-novela histórico-metafórica, apartándose del modelo de las historias noveladas de Walter Scott y acercándose al prototipo manzoniano de la necesidad de la metáfora de los hechos históricos del pasado para referirse a la realidad histórica del presente en que éstos son reescritos, no solamente por la semejanza de los acontecimientos que han marcado la historia en todos los tiempos, sino con un claro propósito de universalización de los mismos². Con Alessandro Manzoni compartía también Consolo la función ideológica de la literatura de oposición al poder: "è una lotta, quella della letteratura, contro il potere, che cerca di cancellare la nostra memoria per non farci avere consapevolezza del presente e non farci immaginare il futuro"3 (Consolo I993: 28). Esta misma idea de anulación de la memoria es reiterada por el autor en la entrevista que concedió a Giuseppe Traina y que el crítico incluyó en las páginas finales de su libro:

Il segno del nostro tempo è la cancellazione della memoria. Lo sviluppo comporta fatalmente un'uniformazione totale, delle masse di consumatori che abbiamo tutti -come si dice in economia politica- la stessa ofelimità, cioè il fatto che tutti desiderino lo stesso oggetto, e questo per il capitale è un vantaggio perché non ha bisogno di differenziare [...]. Se la memoria resiste è un intralcio a questo proceso di omologazione. La cancellazione della memoria, il vivere in un eterno presente, il farci diventare dei soggetti non attivi, obbligati a scegliere. Al di fuori di noi naturalmente c'è l'avallo della pubblicità, di questo nuovo fascismo che è il messaggio pubblicitario. ${ }^{4}$ (Traina, 200I: 134).

En “L'isola perduta di Vincenzino”, en la entrevista que mantiene Ferruccio Parazzoli con Consolo, el mensaje publicitario es definido no como una clara ideología, sino como una mentira de nuestro mundo contemporáneo: "Ma il messaggio pubblicitario non è un'idelogia, è soltanto una menzogna. E qualcosa in continuo movimiento, una volta si sposta verso destra, una volta verso il centro. Ectoplasmi” (Parazzoli, I998: 27).5

\footnotetext{
${ }^{2}$ La novela histórico-metafórica evidencia en terreno literario lo que ha sido uno de los debates teóricos que han estado más presentes en el panorama historiográfico contemporáneo: el influjo del presentismo en el texto histórico puesto que si éste comporta necesariamente una lectura del pasado, lleva inserto a su vez, en sí mismo, una lectura del presente desde el que se construye el discurso narrativo. "Las tesis historicistas de Benedetto Croce, Robin Collingwood o José Ortega y Gasset [...] pusieron de manifiesto el peso real del presente en la labor de quienes leen el pasado" (Aurell, 2005: I6-I7).

3 "Es una lucha, la de la literatura, contra el poder, que intenta cancelar nuestra memoria para que no tengamos conciencia del presente y no nos podamos imaginar el futuro" (La traducción es mía). Cuando en citas sucesivas traducidas del italiano no se remita a la correspondiente edición española, es porque ésta es inexistente.

4 "El signo de nuestro tiempo es la cancelación de la memoria. El progreso comporta fatalmente una uniformidad total, de las masas de consumidores que somos todos - como se dice en economía política- la misma utilidad económica, es decir el hecho de que todos deseen el mismo objeto, y esto para el capital es una ventaja porque no tiene la necesidad de diferenciar [...]. Si la memoria resiste, es un obstáculo en este proceso de homologación. La cancelación de la memoria, el vivir en un eterno presente, el convertirnos en sujetos no activos, obligados a elegir. Fuera de nosotros está el aval de la publicidad, de este nuevo fascismo que es el mensaje publicitario".

5 "Pero el mensaje publicitario no es una ideología, es solamente una mentira. Es algo en continuo movimiento, unas veces se dirige hacia la derecha y otras veces al centro. Ectoplasmas".
} 
Por esta razón, la narrativa memorial de Consolo centra su esfuerzo en la recuperación de los fragmentos del pasado civiles, históricos y culturales porque, una vez reconstruidos, pueden ofrecer una función iluminadora sobre el presente; traduciendo literalmente a Enzo Papa (2003: 185) de "revelación de nuestro propio destino", idea que comparte con este crítico Giulio Ferroni (I999: 208), al referirse al hecho de que el sentido del presente es a veces revelado por los signos resistentes del pasado; signos que, según Paul Ricoeur (1999; 2003), pueden concretarse en los vestigios o las ruinas. Estas huellas del pasado, halladas tras las excavaciones arqueológicas, y que nos permiten recuperar parte de la historia de antiguas civilizaciones evitando su olvido, son recurrentes en gran parte de la producción consoliana; desde el mismo título, incluso, en $\mathrm{Le}$ pietre di Pantalica, en donde el nombre de la Necrópolis Iblea aparece junto a "pietre"; piedras, pues, referentes al pasado, a las ruinas de esa remota civilización, contrapuestas con un alto valor semántico en el imaginario consoliano a "le macerie moderne" (Turchetta, 1990: XI), a los "escombros del presente", resultantes de las tragedias de la Italia actual. El tema de las ruinas y de las excavaciones es llevado por Consolo frecuentemente al campo de su escritura, entendida por él bajo la concepción aristotélica del arte como imitación de la realidad, y metafóricamente, además, como arqueología (argumento que se retomará más adelante en referencia al lenguaje):

Si capisce così comel'insistenza sul tema delle rovine, intese come scavi archeologici, sia un modo di parlare delle condizioni di possibilità della scrittura letteraria, sempre obbligata a ricostruire faticosamente una totalità a partire da pochi e frammentari segni qualche scritta sopra d'una lastra, qualche scena o figura, con la consapevolezza di essere condannata a un'aprossimazione insoddisfacente. ${ }^{6}$ (Turchetta, 1990: X-XI).

La teoría de que los acontecimientos del presente pueden entenderse a partir de los signos del pasado, de las huellas o las ruinas, enlaza también con las ideas historiográficas defendidas por Benedetto Croce (2007: I2), quien afirmaba que sólo un interés por la vida presente nos puede hacer indagar sobre un hecho pasado, el cual, al unirse a la vida presente, ya no responde a un interés pasado, sino actual. La historia del pasado, por lo tanto, nos ayuda a comprender las razones de nuestro tiempo y nos puede hacer vislumbrar el futuro: "Conoscere com'è la storia che vorticando dal profondo viene; immaginare anche quella che si farà nell'avvenire” (Consolo, 2004a: I39). Estas son las palabras conclusivas de Il sorriso del ignoto marinaio que se convierten en el leimotiv de toda la sucesiva narrativa consoliana. No hay una sola obra de este autor cuya base

\footnotetext{
6 "Se entiende así como la insistencia sobre el tema de las ruinas, entendidas como excavaciones arqueológicas, es un modo de hablar de las posibilidades de la escritura literaria, siempre obligada a reconstruir con esfuerzo una totalidad a partir de pocos y fragmentarios signos alguna inscripción sobre una losa, alguna escena o figura, con la certeza de estar condenada a una remota aproximación".

7 “Conocer cómo es la historia que remolineando desde lo hondo llega; imaginar también la que se hará en el porvenir" (Consolo, r981: 195).
} 
histórica no haga referencia metafóricamente al presente en que es escrita, e incluso si la base histórica, como en caso de la crónica, se refiere a la realidad inmediata a su escritura, los contenidos ideológicos que de ella se desprenden, visionariamente, son extensibles a nuestro mundo contemporáneo, en donde las atrocidades cometidas por el terrorismo, la guerra, el fundamentalismo o el racismo siguen presentes en nuestros días, sin dejar pasar por alto otras formas de brutalidad más sutiles. Flora Di Legami (I990: 22), cuando habla de la memoria consoliana, alude acertadamente a una memoria colectiva de hechos dolorosos y trágicos, que reflexiona sobre injusticias sociales que han determinado el presente y que siguen repercutiendo amargamente y tienen su eco en la realidad contemporánea.

Consolo, en un intento de descifrar algunas claves del presente, abarca en el conjunto de su producción literaria un amplio periodo histórico que recorre desde la civilización del siglo XVIII español e italiano hasta acontecimientos más recientes de nuestra contemporaneidad: el fascismo, las consecuencias de las elecciones del 48 en Sicilia, el desembarco de los americanos en la isla, las huelgas de los campesinos en la primera posguerra, la inútil reforma agraria, el mito de la industrialización, los asesinatos cometidos por la mafia, la emigración, sin dejar de pasar, como siciliano, la cita obligada del $R i$ sorgimento, topos histórico recurrente en casi toda la literatura siciliana desde Giovanni Verga a Federico De Roberto, Luigi Pirandello, Giovanni Tomasi di Lampedusa y Leonardo Sciascia, ya que hay que partir de la unidad de Italia para entender las razones del malestar meridional, y para saber cuáles han sido los errores que se han ido cometiendo y acumulando hasta perpetuarse en el tiempo. A Consolo, cuando escribe $I /$ sorriso, no le interesaban los personajes históricos como Giuseppe Garibaldi o Nino Bixio, sino los problemas que se debatían en los años setenta: el papel del intelectual frente a la historia, el valor de la escritura, la historiografía y la literatura, la suerte de los que no tienen la capacidad ni la posibilidad de expresarse y el fracaso de las utopías revolucionarias; y para hablar de todo ello tenía que partir de Sicilia, de su memoria y de su propio lenguaje (Consolo, 1993: 37).

Retablo, otra novela de un alto nivel metafórico, se desarrolla en una Milán del siglo XVIII, pero en ella subyace la idea de una ciudad craxiana, de los años 8o, una ciudad de cinismo y vulgaridad. Esta metáfora queda reflejada claramente en una carta que Fabrizio Clerici, el pintor protagonista, dirige a Teresa Blasco. Los personajes que cita son reconocibles uno por uno en aquellos años en Italia, en la que vencía la Lega Nord en un clima cultural y moral alarmante:

O secol nostro superbo di conquiste e di scienza, secolo illuso, sciocco e involuto! Arrasso, arrasso, mia nobile signora, arrasso dalla Milano attiva, mercatora, dalla stupida e volgare mia città che ha fede solamente nel danee, ove impera e trionfa l'impostore, il bauscia, il ciarlatan, il falso artista, el teatrant vacant e pien de vanitaa, il governante ladro, il prete trafficone, il gazzet- 
tier potente, il fanatico credente e il poeta della putrida grascia brianzola. Arrasso dalla mia terra e dal mio tempo, via via, lontan! ${ }^{8}$ (Consolo, 20ooa: 98 ).

La memoria histórica, pues, como metáfora, como un viaje de regreso al pasado para tomar conciencia del presente, para dar respuestas al dolor del mundo actual, un viaje catártico, a través de la representación literaria, como el que propusieron los escritores alemanes del grupo del 47 (Alexander Kluge, Alfred Schmidt, Uwe Johnson, Hans Magnus Enzensberger), comprometidos en el análisis de las culpas y los misterios del holocausto:

I tedeschi venivano da un'esperienza tremenda, quella del nazismo dei campi di sterminio, e in Germania era in atto una sorta di rimozione di quella grande colpa che li schiacciava, che non li faceva vivere. Il grupo 47 voleva ostinatamente ricordare quello che era successo attraverso la storiografia, additare le colpe, parlarne, invece di seppellire tutto, nel tentativo di provocare una sorta di catarsi collettiva. ${ }^{9}$ (Consolo, I993: 49).

Estas incursiones en la memoria colectiva plasmadas en el texto literario -más revelador que la historiografía al poder desmitificar la historia usando el lenguaje de los vencidos $^{\mathrm{IO}}-$ se convierten en necesidad y testimonio, en un proceso de expiación, que no siempre, sin embargo, llega a cumplirse en la narrativa consoliana, puesto que para Consolo a partir de Il sorriso ya no es posible la utopía de alcanzar una sociedad más armónica, puesto que Ítaca, metáfora de Sicilia y del mundo contemporáneo, la isla madre donde Ulises vuelve a reconciliarse con su destino una vez superados los monstruos generados por sus remordimientos, ha sido devastada, destruida por monstruos concretos que, se-

\footnotetext{
8 “ $\mathrm{iOh}$ siglo nuestro orgulloso de conquistas y de ciencia, siglo iluso, necio e indeseado! Apartado, apartado, mi noble señora, apartado de la Milán activa, mercantil, de la estupida y vulgar ciudad mía, que confía sólo en el dinero, donde impera y triunfa el impostor, el fanfarrón, el charlatán, el falso artista, el hipócrita y lleno de vanidad, el gobernante ladrón, el cura ventajista, el gacetillero prepotente, el creyente fanático y el poeta de la pútrida mugre de Brianza. ¡Apartado de mi tierra y de mi tiempo, a tumbos, lejos!” (Consolo, I995a: Io9-IIo).

9 "Los alemanes venían de una experiencia tremenda, la del nacismo de los campos de exterminio, y en Alemania se produjo una especie de remordimiento de la gran culpa que los oprimía, que no los dejaba vivir. El grupo del 47 quería recordar obstinadamente lo que había ocurrido a través de la historiografía, mostrar los crímenes, hablar de ellos, en lugar de sepultarlo todo, con la intención de provocar una especie de catarsis colectiva”.

Io Esta idea de que el relato literario puede ser un instrumento más apropiado que la historia profesional para representar el pasado se hizo patente en los trabajos del historiador anglosajón Hayden White (2OIO: I3) producidos a partir de la década de los años setenta, en plena efervescencia del llamado "giro lingüístico" propuesto por autores como Michel Foucault o Jacques Derrida, y que significó una llamada de atención hacia la importancia de lenguaje, de la narración, en el discurso histórico. White, gran cultivador de esta corriente, rechazó la distinción -mantenida sin generar problemática desde Aristóteles hasta el siglo XIX con el nacimiento de la novela histórica- entre relato histórico y relato de ficción basada en el criterio de que relatan, respectivamente, acontecimientos reales o imaginarios. White sostenía que la historia era también una parte importante de la retórica, que la vinculación con el pasado es siempre emotiva, y que los "mecanismos" poéticos que determinan la producción de relatos históricos son los mismos que determinan los relatos literarios, relatos estos últimos que muchas veces además no son ficcionales teniendo como objetivo la "representación realista de la realidad" (White 2003: 9, 57; cfr. además la nota 22 de este artículo). Los presupuestos teóricos mantenidos por White no sólo supusieron una ruptura con los grandes frentes de renovación temática, metodológica y epistemológica de los años setenta (la historia de las mentalidades de la tercera generación de la escuela francesa de Annales y la historia social de la escuela alemana de Bielefeld) sino que marcaron un hito en la filosofía de la historia encendiendo un acalorado debate hoy en día más apagado, pero no del todo concluido.
} 
gún el autor (Consolo, I993: 52; 1995b: 6), ya no surgen del mar, sino del subconsciente, de los abismos, y se han objetivizado. Después de los terrores de Hiroshima y de Auschwitz, después de los crímenes del régimen de Stalin y de las masacres perpetradas en Sarajevo, después de todos los horrores de hoy, que no son sino una prolongación de los existentes a lo largo de toda la historia de la humanidad, esos monstruos profetizados por Franz Kafka o por Robert Musil, por Thomas Eliot, James Joyce o Giovanni Pirandello, se han hecho reales. Estos son los monstruos que la literatura, la novela, insiste Consolo, debe afrontar, si no se quiere caer en la alienación, en la fuga, en la complicidad:

Nella modernità, le colpe non sono più soggettive, ma oggettive, sono della storia. [...] (tutti noi abbiamo scatenato le guerre, creato i campi di sterminio, le pulizie etniche, lasciamo morire per fame la stragrande maggioranza dell'umanità...). Nessun viaggio penitenziale e liberatorio è ormai possibile. Itaca non è più raggiungibile. Questo, secondo me, lo scrittore oggi ha il compito di dire, di narrare. Narrare oggettivamente in terza persona, dei mostri, delle mostruosità che abbiamo creato, con cui, privi ormai di memoria, di rimorso, privi dell'assillo di raggiungere una meta, da alienati, felicemente conviviamo. ${ }^{\text {II }}$ (Consolo, 1999: 22).

Siente, por consiguiente, Consolo, para expresar en su escritura la concepción del mundo en que vivimos, la exigencia de la metáfora del nostos, de la cita constante del viaje de regreso narrado en la Odisea, que del imaginario griego y luego latino ha pasado a convertirse en referente inagotable de nuestra literatura occidental (Consolo, 2OOI: 263270). De hecho, como ya ha referido la mayor parte de la crítica consoliana, y de forma más monotemática Eduard Vilella (2005: 32), que considera la Odisea como un auténtico hipotexto para una lectura de Consolo, en la mayoría de sus novelas los protagonistas emprenden un viaje no sólo geográfico (de Lipari a Cefalú, de Milán a Sicilia, de Sicilia a Tunez,...) sino también catártico, como el de Ulises, de la mera existencia a la Historia ${ }^{22}$.

\footnotetext{
II "En la modernidad, los crímenes no son ya subjetivos sino objetivos, son de la historia. (Todos nosotros hemos desencadenado las guerras, creado los campos de exterminio, las limpiezas étnicas, dejamos morir de hambre a la gran mayoría de la humanidad...). Ningún viaje expiatorio y liberador es ya posible. Itaca ya no es alcanzable. Esto, según yo, es lo que el escritor tiene el deber de decir, de narrar. Hablar objetivamente en tercera persona de los monstruos, de las monstruosidades que hemos creado, con las que exentos de memoria, privados del estímulo de alcanzar una meta, como alineados, felizmente convivimos". La escritura no cambia el mundo, pero es un modo de defenderse contra la impotencia, como acierta a decir Silvano Nigro en el prólogo de un volumen que recoge una serie de Crónicas escritas por Consolo, de publicación póstuma a la muerte del autor (Consolo, 2OI3: II).

${ }^{12}$ Ulises renuncia a la vida eterna que le es ofrecida por Calipso y opta por una realidad temporal, histórica, humana cuyo punto final de llegada es la muerte. En L'olivo e lolivastro (Consolo, I994) el mismo título (El Olivo y el acebuche), anticipa el alcance significativo que va tener en esta obra consoliana la cita intertextual del viaje del Odiseo homérico, como contrapunto al emprendido en la novela por un viajero innominado, pero identificable con el autor. En la odisea homérica el "olivo" y el "acebuche" que nacen de un mismo tronco, le sirven a Odiseo de cobijo cuando llega a Esqueria de los Feacios. Consolo ha visto en esta imagen un símbolo de una bifurcación, de dos senderos o destinos que se abren en la vida de un hombre, en la historia de un país. El "olivo" simboliza la civilización y el "acebuche" la barbarie. "Mi è sembrato il simbolo più pregnante della Sicilia, la quale diventa sempre, come si dice, metafora dell'Italia (dell'Europa, del mondo?)" (Consolo, I995b: 5). ("Me ha parecido el símbolo más identificativo de Sicilia, que se convierte cada vez más, como se dice, en metáfora de Italia, de Europa, del mundo"); cfr. además Isole dolci del Dio (Consolo, 20O2). El viajero consoliano - moderno Ulises- verifica que, aunque el acebuche haya invadido el campo y aunque la isla esté ya destruida y él se haya visto obligado a volver a partir, condenado a vagar de un sitio a otro (Consolo, I999: 25-26), todavía quedan en Sicilia, la tierra por la que viaja, huellas de civilización, de amor por la memoria del pasado (Traina, 2OOI: 98).
} 
Un viaje que los lleva a todos - el barón Mandralisca, Petro Marano, Gioacchino Martínez, Fabrizio Clerici y todos los alter egos consolianos-, encadenados por la misma trama histórico-simbólica, a una toma de conciencia humana y a un creciente conocimiento de los hechos históricos y sociales. A todos ellos los une una idéntica honestidad intelectual, que, sin embargo, no les preserva de la desilusión y del fracaso de su compromiso social y literario (Bellia, 2003: 276-277). Literario en el sentido de que la metaficción -recordemos la función de escritores que Consolo atribuye a algunos de los personajes con los que pretende identificarse - aparece continuamente unida a la incapacidad de encontrar la palabra. Tema este, el de la afasia, que ha preocupado al autor desde los comienzos de su escritura -y que desarrolla ampliamente con posterioridad en Nottetempo, casa per casa (Consolo, 20IO)-, apartándose desde aquellos primeros años del proyecto literario de los escritores del grupo del 63, que proponían una ideología lingüística muy cercana a la del Futurismo, a la del decálogo de Filippo Tommaso Marinetti: "il disordine sintattico e semántico come rispecchiamento del disordine della società" decir, una desarticulación de la lengua, una lengua absolutamente artificial que se apartaba por completo no sólo de la corriente neorrealista, sino del lenguaje de la tradición literaria italiana. Para Consolo esta propuesta vanguardista era totalmente desacertada porque la función de la literatura no es la de unirse a la afasia del Poder, sino la de combatirlo precisamente con la palabra. En numerosas ocasiones Consolo se ha referido al discurso lingüístico que a este respecto hace Pier Paolo Pasolini (I972) en "Nuove questioni linguistiche" donde deja claro, en ese momento de transformación lingüística ocasionada por el neocapitalismo, la diferencia existente entre las propuestas literarias vanguardistas y las experimentales.

Consolo, partiendo de las experimentaciones lingüísticas de Carlo Emilio Gadda y Pier Paolo Pasolini' ${ }^{14}$, y sin olvidar tampoco la lección de Giovanni Verga -el primer gran revolucionario estilístico de la literatura moderna italiana-, opta por un código lingüístico propio, repleto de voces cultas, procedentes de la tradición literaria, arcaicas y dialectales, organizadas en una prosa fuertemente marcada por la musicalidad de la métrica, por el ritmo de la poesía. De hecho, algunos críticos consolianos -Torricelli (I989: I93-I95) y Ternullo (I998: II-I2) - hablaban de una auténtica poesía enmascarada tras la apariencia de la prosa y ejemplificaban esta idea disponiendo en versos los periodos sintácticos más rítmicos del autor. Esta tendencia hacia la prosa poética es propuesta por Consolo en un intento de verticalizar la novela, de devolverle la dignidad perdida en el mundo contemporáneo en que el género se ha sometido a las leyes de la oferta y la demanda, del marketing, de los sondeos del gusto del público y de las ventas, prostituyéndose, por ello, la novela con un lenguaje de fácil comunicación, absolutamente homologado, corrompido,

\footnotetext{
I3 "El desorden sintáctico y semántico como reflejo del desorden de la sociedad".

${ }^{\text {I4 }}$ Aunque las soluciones expresivas de Consolo son muy diferentes a las de Gadda y Pasolini, con este último escritor comparte un profundo discurso sobre los efectos nocivos de la homologación antropológica, que destruye la diversidad existente entre las civilizaciones y las culturas arcaicas, auténticas, populares (Gioviale, 1985: 50). A ambos escritores les une el propósito de la conservación de la memoria de las culturas locales.
} 
degradado de acuerdo con las exigencias y las líneas de mercado de la empresa editorial. Según Consolo, la novela está muriendo o está ya muerta, e insiste en que no se trata del eterno ritornello de vanguardia porque nunca como hoy se han producido tantas novelas y nunca se han volatilizado tantas (Puglisi: 20o8: 289). Queda, por lo tanto, en manos de la poesía, imperturbable e ignorada, hija de la memoria, como la llama Consolo, recuperar la dignidad de la novela, haciendo de la escritura narrativa una prosa altamente expresiva; proyecto que consigue el autor mediante la creación prosística -a través de la distribución de los acentos y las sílabas-de auténticos endecasílabos y heptasílabos, de asonancias, de elaboradas y plásticas aliteraciones y de un sin fin de enumeraciones nominales donde un término inicia una mágica cadena de sinónimos y analogías con el fin de renombrar todas las cosas, de hacerlas visibles al lector, de abarcar, como en un cuadro, todas las imágenes presentes en la realidad artística que está contando. Consolo se definía a sí mismo, y así es visto además por gran parte de sus críticos, como un arqueólogo del lenguaje que utiliza la memoria como instrumento de excavación, capaz de recuperar, de sacar a la luz, dilatando hasta lo inimaginable los más variados campos semánticos, todo un patrimonio lexical, un legado lingüístico procedente de las civilizaciones que dejaron huellas en su isla. Palabras extraídas del olvido a través de la recuperación memorial, ilocalizables en los grandes diccionarios italianos, cuya etimología puede encontrarse en el griego, en el árabe, en el francés, en el español y en una lengua galo-itálica, que llegó a Sicilia con la conquista normanda: el sanfratellano, que se ha conservado en las colonias lombardas de Sicilia. En definitiva, un plurilingüismo o "plurivocità", como la llamó Cesare Segre (I987: XIV), de una gran resonancia histórica, que Consolo organiza en el interior de una prosa poética donde no falta además el siciliano, el siciliano italianizado o el napolitano:

Él [Consolo] está convencido de la riqueza de la base lingüística dialectal y considera, por tanto, necesario mantener esa multiplicidad procedente del patrimonio lingüístico y cultural de los dialectos, pero defiende igualmente la necesidad de una lengua italiana que mantenga su memoria histórica, considerada no como un anacronismo, sino como una especie de arca donde siempre es posible buscar la palabra o la opción lingüística adecuada. Así, [para este autor] la defensa de la lengua es defensa de la memoria, de las características conformadoras de la autonomía y de la identidad de una nación, hasta el punto de convertirse en una defensa de su visión del mundo y de su ética. (González, 2008: 89).

Consolo elabora, pues, su propio vocabulario poético extrayendo palabras de las más diversas fuentes y dispares yacimientos lingüísticos, palabras que representan cosas verdaderas, visibles y concretas, que designan objetos desaparecidos con la industrialización, y palabras de una gran belleza sonora, cuyo significado responde a elementos de la naturaleza actualmente devastados. Términos de plantas, animales, conchas, mercancías, jardines, ciudades de antiguas civilizaciones, divinidades míticas,... caen en cascada, una tras otra ininterrumpidamente, por su fraseología con una fuerza lingüística capaz de aniquilar la vacuidad terminológica de los medios de comunicación de masas, de la 
tecnología y de la burocracia. Enumeraciones nominales, en definitiva, con el poder de detener el tiempo, de convertirse en guardianas de la memoria, de recuperar los gestos primigenios del ser humano, cuando aún era capaz de dar nombres, de reconocer la realidad en la que vivía y de escuchar la naturaleza que lo rodeaba.

Consolo deja explícitamente patente esta ideología lingüística en I linguaggi del bosco, relato autobiográfico perteneciente a Le pietre di Pantalica, donde el autor cuenta de su amistad infantil con la hija del guardabosques, de nombre Amalia, que se convirtió en su maestra "lexicográfica” 5 :

Dietro i porci e le capre al pascolo, fu lei a rivelarmi il bosco, il bosco più intricato e segreto. Mi rivelava i nomi di ogni cosa, alberi, arbusti, erbe, fiori, quadrupedi, rettili, uccelli, insetti... E appena li nominava, sembrava che da quel momento esistessero. Nominava in una lingua di sua invenzione, una lingua unica e personale, che ora poco a poco insegnava a me e con la quale per la prima volta comunicava. Ma Amalia poi conosceva altri linguaggi: quello sonoro, contratto, allitterato, con cui parlava alle bestie, conosceva il sampieroto, con quale comunicava con la famiglia; conosceva il sanfratellano e il siciliano coi quali comunicava cogli estranei. ${ }^{16}$ (Consolo, I990: I5I).

Para facilitar la búsqueda e inserción de este lenguaje en sus novelas, Consolo recurre a la ambientación histórica y geográfica; es decir, a la posibilidad de escribir sobre los lugares de su memoria: "Sono luoghi che avevo visto, in cui ero nato e cresciuto. Restituivo quei luoghi anche nei toponimi” ‘z, dirá en la entrevista concedida a Giuseppe Traina (2OOI: I28). Y efectivamente, estos lugares son llamados en terreno literario por su nombre geográfico real, aunque algunos de ellos como el cañón de "L’inganno" o "il Furiano" adoptan naturalmente otros significados metafóricos en Lo spasimo di Palermo (Consolo, 2OOob), al traspasar las barreras de su fisicidad y convertirse en espacios emocionales transitados en ese momento por el personaje protagonista, Gioacchino, un niño que se culpa de la muerte de su padre durante la ocupación alemana y que se siente abatido en medio de un guerra de mayores que no acierta a comprender.

Otro lugar de un gran valor metafórico es Cefalù, ciudad, por otra parte, perteneciente a una parcela memorial del autor no tan remota, pero que estudiará a fondo, trazándose un mapa topográfico de sus calles, por haberla elegido como escenario re-

\footnotetext{
I5 Gianni Turchetta piensa que Amalia, aparte de ser un personaje real, puede ser un alter ego del propio Consolo por compartir con él la fascinación por el lenguaje, por la creación de nuevas palabras (Consolo, I99O: XIII).

I6 “Tras los cerdos y las cabras pastando, fue ella quien me “reveló” el bosque, el bosque más intrincado y secreto. Me revelaba los nombres de cada cosa: árboles, arbustos, hierbas, flores, cuadrúpedos, reptiles, pájaros, insectos... y en cuanto los nombraba, parecía que existiesen desde ese momento. Los nombraba en una lengua de su propia invención, una lengua única y personal, que poco a poco me iba enseñando y con la que se comunicaba por primera vez. Pero Amalia además conocía otros lenguajes: el sonoro, contraído, aliterado, con el que le hablaba a las bestias, conocía el sampieroto, con el que se comunicaba con la familia; conocía el sanfratellano y el siciliano, con el que se comunicaba con los extraños".

I7 “Son lugares que había visto, en los que había nacido y crecido. Utilizaba esos lugares también en los topónimos”.
} 
currente -Il sorriso, Retablo, La corona e le armi- por el que sus personajes pasean, se pierden o deambulan.

Cefalù es la puerta de la Sicilia occidental, de la razón y de la historia, donde el hombre ha dejado su huella; y los personajes que se encuentran ante la catedral de Cefalù sufren una especie de raptus, una revelación que les lleva a descubrir los signos de la historia. El faro que alumbra el mar desde esta misma localidad simboliza, por otra parte, la invitación al viaje, al conocimiento del mundo, siendo su luz la claridad que enciende intermitentemente las tinieblas del presente, en un deseo de penetrar en el misterio de la existencia.

Pero Consolo no sólo nutre su prosa de la metáfora histórica y topográfica o de memoria lingüística, como hasta aquí se ha venido analizando, puesto que junto a sus propias palabras aparecen también innumerables citaciones, presentadas de diferentes formas (Scuderi, I998: 84-9I), procedentes no sólo de la memoria literaria universal (recordemos, por ejemplo, el vínculo intertextual con la Odisea), sino de obras de carácter filosófico y de erudición científica. El conjunto de la producción consoliana es, por tanto, de tipo palimpséstico, una escritura sobre otras escrituras, convirtiéndose estas últimas en verdaderos instrumentos metafóricos de su lenguaje. Tema éste que por su amplitud y el límite de estas páginas merecería un estudio aparte. Tan solo reseñar brevemente que la identidad literaria de este autor se construye a partir de dos grandes modelos de escritura, Leonardo Sciacia y Lucio Piccolo - amigos, además, de Consolo-. Del primero, adquiere el compromiso histórico y civil, la necesidad de denunciar las barbaries de la sociedad contemporánea; del segundo, el lenguaje mítico, poético. Formalmente, sin embargo, en el modo de estructurar narrativamente los hechos históricos o de elegir un determinado léxico, se aparta de uno y de otro, así como de los compañeros de generación de Leonardo Sciascia (Alberto Moravia e Italo Calvino):

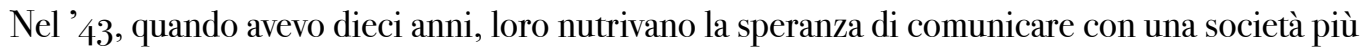
armonica sicché la loro scelta illuminista e razionalista era nel senso della speranza. Quando io sono nato come scrittore, questa speranza era caduta e ho cercato di raccontare perché si era restaurato un assetto político che non era come si sperava, ancora una volta iniquo, che lasciava marginalità, oppressioni e sfruttamento. Ho scelto il registro espressivo e sperimentale non vedendo una società armonica con la quale comunicare. La speranza che avevano nutrito quelli che mi avevano preceduto in me non c'era più. ${ }^{18}$ (Consolo, 2004b).

Así pues, opta por una escritura en vertical, y no sólo a través del lenguaje poético y metafórico, sino sirviéndose de una total desarticulación de la estructura narrativa de

\footnotetext{
I8 “En el 43, cuando tenía diez años, ellos albergaban la esperanza de comunicarse con una sociedad más armónica así que su lección ilustrada y racionalista era en el sentido de la esperanza. Cuando yo nací como escritor, esa esperanza se había perdido e intenté contar por qué se había restaurado un orden político que no era como se esperaba, que continuaba siendo inicuo, que generaba marginalidad, opresión y explotación. Elegí el registro expresivo y experimental no viendo una sociedad armonica con la que comunicarme. La esperanza que había alimentado a los que me precedieron ya no existía en mí”.
} 
la novela histórica decimonónica. Una narración confiada, además, a la memoria es acertado que opere como ésta; es decir, por retazos o fragmentos. Elección que le lleva en Il sorriso a poder ofrecer distintas perspectivas de los hechos ocurridos en Alcàra Li Fusi ${ }^{19}$, pudiendo dar voz a los oprimidos, a las voces marginadas por la historia que se han quedado al margen de la memoria colectiva. Con este fin, entre los capítulos de invención, que hablan también de personajes históricos, y los documentos colocados en apéndice, alejados del contexto-que sintetizan el devenir de los hechos que Consolo se niega a narrar porque ya han sido narrados por los cronistas-, aparece también la transcripción de los grafitis que los presos de la revuelta dejaron escritos en las paredes de la cárcel; grafitis que son testimonio escrito de quienes no gozaban del derecho de que sus voces fuesen tenidas en cuenta y recordadas. Toda esa memoria sepultada es la que Consolo trata también de recuperar, porque unidos los fragmentos, recompuestas todas las piezas de la Historia, se crea un mutuo diálogo entre diversas visiones del mundo en grado de ofrecer una reconstrucción de los hechos más cierta. Parece que Consolo ha aprendido bien la lección historiográfica que tanto le interesaba: "Una storia senza relazione col documento sarebbe una storia inverificabile" ${ }_{20}$ (Croce, 2007: 13). En Il sorriso, sin embargo, hay una desconfianza de acercamiento a la verosimilitud y se recurre a la utopía de la esperanza, de que sean los oprimidos quienes cuenten su historia. Este es el pensamiento de Mandralisca, del intelectual que para redimirse de su culpa, para limpiar su conciencia, deja su patrimonio al pueblo de Cefalù con la esperanza de que las nuevas generaciones "la storia loro, la storia, la scriveran da sé" (Consolo, 2004a: II7).

Según lo apenas expuesto, y siguiendo la opinión del propio Consolo y de Hayden White (referida ampliamente también en nota Io), a la memoria le correspondería en la literatura el deber de restablecer ciertas verdades históricas, de neutralizar los intentos de instrumentalización del poder y de levantar conciencias ${ }^{22}$. Pero también la memoria

\footnotetext{
${ }^{19}$ Se trata de una revuelta campesina que tuvo lugar el I7 de mayo de i86o, con efectos sangrientos, en Alcàra Li Fusi, pueblo siciliano de la provincia de Messina cercano al del autor (Sant'Agata di Militello). Los braceros y campesinos, desesperados ante las vejaciones e infrahumanas condiciones de vida a las que eran sometidos por los terratenientes, y creandose expectativas de justicia social ante el inminente desembarco de los garibaldinos en la isla, asaltaron un edificio público (el Casino dei civili) causando la muerte a once personas. Tras cuarenta días de saqueos, incendios, devastación de cosechas y apropiación de casas y de fincas que siguieron a la revuelta, actos todos ellos dirigidos por los cabecillas revolucionarios que se hicieron con el poder del pueblo, el coronel garibaldino Giovanni Interdonato apresó a algunos de los rebeldes y, después de un rápido proceso, éstos fueron ajusticiados. Este episodio histórico, al que la historiografía no ha prestado mucho interés, ocupa el centro neurálgico de la novela consoliana, abriendo un debate entre el carácter más o menos popular del Risorgimento y la relación existente entre los acontecimientos históricos y la realidad de los estratos sociales mas bajos de la población meridional. Un interesante y esclarecedor artículo sobre los motivos que impulsaron a la revuelta de Alcàra Li Fusi es el de Pietro Siino (I980). El periodo histórico en cuestión es tratado por Mack Smith (1970).

20 "Una historia que no guardase relación con el documento, sería una historia inverificable”.

2I “su historia, la historia, la escribirán por sí mismos” (Consolo, I981:I62).

${ }^{22}$ Hayden White, analizando algunas obras literarias, llegó a decir, por ejemplo, de la obra de Primo Levi Se questo è un uomo, que no es tanto una historia como una pieza privilegiada de evidencia histórica y que debería ser un modelo de la clase de relato que los historiadores, trabajando a partir de una variedad de fuentes, podrían desear haber sido capaces de producir como un relato de la vida en los campos de exterminio nazis. El libro de Primo Levi "nos cuenta no solo lo que sucedió en Auschwitz entre su llegada en octubre de r944 y junio de r945; nos cuenta -más importante aún- lo que sintió al haber sido la víctima de una clase de humillación que los campos de exterminio habían transformado en arte" (White, 2OIO: 2I3). Vincenzo Consolo en la entrevista concedida a la Rai para el programa "Scrittori per un anno", hablando en concreto de Retablo, también se refirió al hecho de que la novela histórica puede ser más real que los estudios históricos puesto que la literatura representa los sentimientos del ser humano, mientras que la historia o la política tratan sólo de su aspecto externo y civil, de la situación del hombre en el contexto social e histórico.
} 
en la narrativa consoliana, como se ha comentado anteriormente, puede entenderse metafóricamente como cifra interpretativa del presente, como pieza clave de nuestra identidad personal y como salvadora, a través de la recuperación de un lenguaje olvidado, de la barbarie cultural, de la masificación, del proceso de homologación constante y progresivo causado por el neocapitalismo. Una memoria, como acierta a definir Natale Tedesco (2009: I37), no cristalizada, sino dialéctica, capaz de remover el presente y de agitarse en el interior de su propio pasado ${ }^{23}$.

En Lunaria, reescritura consoliana de un poema de Lucio Piccolo titulado Le esequie della luna -caso ejemplar de hipertexto siguiendo los preceptos teóricos planteados en Palimpsestos de Gerard Genette (I989: I4) - , la luna, símbolo del eterno retorno, de la luz de la cultura, de la creación artística, de la autenticidad humana, renace, después de su caída en el mundo, en una "Contrada sin nombre", y no lo hace casualmente allí, sino porque en ese lugar se conserva “la memoria, l’antica lingua, i gesti essenziali, il bisogno dell'inganno, del sogno che lenisce e che consola”"24 (Consolo, 2003: 122).

Consolo recurre al símbolo lunar, a la luz de la metáfora del pasado -histórico, lingüístico y literario- para alumbrar la oscuridad generada por la afasia del Poder y la cultura de masas del mundo contemporáneo.

\footnotetext{
${ }^{23}$ Sobre la memoria en la escritura de Vincenzo Consolo, cfr. Esposito y Budor (2OIO).

24 "la memoria, la antigua lengua, los gestos esenciales, la necesidad de la ilusión, del sueño que apacigua y que consuela" (Consolo, 2003: I23).
} 


\section{Referencias bibliográficas}

- Aurell, J. (2005). La escritura de la memoria. De los positivismos a los postmodernismos. Valencia: Universidad de Valencia.

- Bellia, G. (2003). "L'obliquo percorso della memoria. La scrittura di Vincenzo Consolo tra storia, ritualità e sdegno". En Massimo Naro (Ed). Sub specie typographica. Domande radicali negli scrittori siciliani del Novecento (pp. 263-286). Caltanissetta-Roma: Salvatore Sciascia editore.

- Consolo, V. (I98I). La sonrisa del ignoto marinero. Esther Benítez (Ed). Madrid: Alfaguara.

- Consolo, V. (I990 [1988]). Le pietre di Pantalica. Milán: Oscar Mondadori.

- Consolo, V. (ı993). Fuga dall'Etna. La Sicilia e Milano, la memoria e la storia. Roma: Donzelli.

- Consolo, V. (I994). L'olivo e l'olivastro. Milán: Arnoldo Mondadori.

- Consolo, V. (r995a). Retablo. Juan Carlos Gentile (Ed). Barcelona: Muchnick Editores.

- Consolo, V. (I995b). 29 aprile r994: cronaca di una giornata. Nuove effemeridi, VIII (29. I), $4-7$.

- Consolo, V. (1996). Per una metrica della memoria. Cuadernos de Filología Italiana, 3, 249-259.

- Consolo, V. (1999). Il viaggio di Odisseo. Milán: Bompiani.

- Consolo, V. (2000a [1987]). Retablo. Milán: Oscar Mondadori.

- Consolo, V. (200ob [1998]). Lo spasimo di Palermo. Milán: Oscar Mondadori.

- Consolo, V. (200I [I999]). Diqua dal faro. Milán: Oscar Mondadori.

- Consolo, V. (20O2). Isole dolci del Dio. Brescia: L'Obliquo.

- Consolo, V. (2003 [1985)]. Lunaria. Irene Romera Pintor (Ed). Madrid: Centro de Lingüística Aplicada Atenea.

- Consolo, V. (2004a [1976]). Il sorriso dell'ignoto marinaio. Milán: Oscar Mondadori. 
- Consolo, V. (2004b). Consolo: figlio di tanti padri-Rai Letteratura [Entrevista a Consolo de Gianni Bonina, I6 de junio 2004]. Obtenido el 28 de octubre 2014 desde http: / /www.letteratura.rai.articoli-programma/consolo-fliglio-di-tanti padri/ı35I/default.aspx Consolo.

- Consolo, V. (2Оіо [1992]). Nottetempo, casa per casa. Milán: Oscar Mondadori.

- Consolo, V. (20I3). Esercizi di cronaca. Palermo: Sellerio Editore.

- Croce, B. (2007). Teoria e storia della storiografia. Nápoles: Bibliopolis.

- Esposito, F.; Budor, D. et al (2OIO). Scrittura e memoria in V. Consolo. Microprovinciana, 48 (monográfico sobre Vincenzo Consolo).

- Di Legami, F. (1990). Vincenzo Consolo. La figura e l’opera. Marina di Patti: Pungitopo.

- Ferroni, G. (I999). Vincenzo Consolo. En Passioni del Novecento (pp. 203-232). Roma: Donzelli editore.

- Genette, G. (i989). Palimpsestos. La literatura en segundo grado. Celia Fernández Pietro (Ed.). Madrid: Taurus.

- Gioviale, F. (1985). Vincenzo Consolo: la memoria épico-lirica contro gli inganni della storia. En La narrativa sciliana d'oggi, successi e prospettive (pp. 47-54). Palermo: Centro Pitré.

- González Martín, V. (2008). La Nuova Questione della lingua en Vincenzo Consolo. En Irene Romera Pintor (Ed). La pasión por la lengua: Vincenzo Consolo (pp. 8I-96). Valencia: Consejería de Educación.

- Mack Smith, D. (1970). Storia della Sicilia medievale e moderna. Il Risorgimento 1837-1860, II. Bari: Laterza.

- Papa, E. (2003). Vicenzo Consolo. Ritratti critici contemporanei. Belfagor, II (Año LVIII), I79-I98.

- Parazzoli, F. (1998). L'isola perduta di Vincenzino. En Il gioco del mondo. Dialoghi sulla vita, i sogni, le memorie con Lalla Romano, Vincenzo Consolo, Luciano De Crescendo, Giuseppe Pontiggia, Susanna Tamaro, Antonio Tabucchi, Lara Cardella, Gina Lagorio, Alberto Bevilacqua, Luce D'Eramo (pp. 23-33). Cinisello Balsamo (Milán): San Paolo.

- Pasolini, P. P. (1972). Nuove questioni linguistiche. En Empirismo eretico (pp. 5-25). Milán: Garzanti.

- Puglisi, S. (2008). Soli andavamo per la rovina: saggio sulla scrittura di Vincenzo Consolo. Roma: Bonanno. 
- Ricoeur, P. (1999). La lectura del tiempo pasado: Memoria y olvido. Gabriel Aranzueque (Ed.). Madrid: Arrecife.

- Ricoeur, P. (2003). La memoria, la historia, el olvido. Agustín Neira (Ed.). Madrid: Editorial Trotta.

- Scuderi, A. (1998). Scrittura senza fine: Le metafore malinconiche di Vincenzo Consolo. Enna: Il lunario.

- Segre, C. (i987). Introduzione. En V. Consolo. Il sorriso dell'ignoto marinaio (pp. VXVII). Milán: Mondadori (Oscar Oro).

- Siino, P. (1980). Una pagina sconosciuta della rivoluzione siciliana del ı86o. I fatti di Alcàra Li Fusi. Società Siciliana per l'Amicizia fra i Popoli. Obtenido el 8 de febrero de 20I4 desde http://www.amiciziafraipopoli.org/documenti-siialcara.htm.

- Tedesco, N. (2009). Vincenzo Consolo. Le pietre di Pantalica. En L'occhio e la memoria. Interventi sulla letteratura italiana (pp. I35-137). Acireale-Roma: Bonnano editore.

- Ternullo, C. (1998). Vincenzo Consolo. Dalla «Ferita» allo «Spasimo». Catania: Prova d'autore.

- Torricelli, P. (i989). Lo specchio infranto. L'esercizio della lingua nella prosa di Consolo. Lingua e letteratura, VII (I3), I85-2I9.

- Traina, G. (2OOI). Vincenzo Consolo. Fiesole: Cadmo.

- Turchetta, G. (1990). Fra le rovine. En Vincenzo Consolo. Le pietre di Pantalica (pp. XXIII). Milán: Oscar Mondadori.

- Vilela, E. (2005). Nostos y Laberinto. Quaderns d'Italià. Leggere Vincenzo Consolo, Io, $3^{\mathrm{I}-47}$.

- White, H. (2003). El texto histórico como artefacto literario y otros escritos. Veronica Tozzi (Ed). Barcelona-Buenos Aires- México: Ediciones Paidós-I.C.E. de la Universidad Autónoma de Barcelona.

- White, H. (2010). Ficción histórica, historia ficcional y realidad histórica. Veronica Tozzi (Ed). Buenos Aires: Prometeo Libros. 